\title{
Influência da Glândula Pineal sobre a Ingestão de Água e NaCl em Ratas Normais e Ooforectomizadas
}

\author{
Influence of Oophorectomy and Pinealectomy on Walter and $\mathrm{NaCl}$ Ingestion by Adult Rats
}

José Maria Soares Jr. ${ }^{1}$, Edmund Chada Baracat ${ }^{1}$, Shirley Oliveira ${ }^{2}$, Mauro Abi Haidar ${ }^{1}$, Manoel Jesus Simões ${ }^{1}$, Luiz Carlos Reis ${ }^{2}$

\section{RESUMO}

Objetivo: avaliar a influência da pineal sobre a ingestão de água e de $\mathrm{NaCl}$ em ratas normais e ooforectomizadas.

Métodos: utilizaram-se $48(n=48)$ ratas adultas, divididas ao acaso em quatro grupos: $G I$ mantidas sem manipulação, servindo como controle $(n=20)$; GII - submetidas à ooforectomia bilateral ( $n=8)$; GIII - submetidas à pinealectomia ( $n=12) ;$ GIV - submetidas à ooforectomia bilateral e à pinealectomia $(n=8)$. A seguir, todos os animais foram mantidos em gaiolas individuais; após três semanas. Determinou-se diariamente a fase do ciclo por esfregaço vaginal e anotou-se diariamente o volume ingerido de água e $\mathrm{NaCl}$ a 0,25 $\mathrm{M}$, por aproximadamente três meses.

Resultados: 1) as ratas submetidas somente à pinealectomia apresentaram maior freqüencia da fase de estro, sendo que algumas entraram em estado de estro permanente; 2) o consumo de líquidos (água e solução salina) não se alterou durante as diferentes fases do ciclo estral; 3) as ratas do grupo submetido à ooforectomia tiveram maior consumo de água, sendo que a pinealectomia nesses animais restabeleceu o consumo normal de água; 4) os animais ooforectomizados e os ooforectomizados e pinealectomizados mostraram redução do consumo médio de solução salina.

Conclusões: os dados obtidos sugerem que a glândula pineal poderia modular a ação dos esteróides ovarianos sobre a ingestão de sal e água em ratas adultas.

PALAVRAS-CHAVE: Pineal. Metabolismo. Ooforectomia.

\section{Introdução}

A pineal é uma glândula que participa da regulação dos ciclos biológicos de diversos animais, atuando sobre diferentes sistemas ${ }^{17}$. Seu principal produto é a melatonina ${ }^{18,19,22}$. A pineal exerce importante ação antigonadotrófica, tendo papel específico no controle da atividade do ciclo sexual

${ }^{1}$ Departamento de Tocoginecologia da Universidade Federal de São Paulo/Escola Paulista de Medicina (UNIFESP/EPM)

${ }^{2}$ Departamento de Fisiologia da Faculdade de Medicina do Triângulo Mineiro (FMTM)

Correspondência:

Edmund Chada Baracat

Disciplina de Ginecologia - UNIFESP/EPM

Rua Napoleão de Barros, $740-7^{\circ}$ andar

04023-900 - São Paulo - SP

Fone: (11) 576-4100 de $\operatorname{ratas}^{10,11}$ e possivelmente de outros mamíferos, inclusive da espécie humana ${ }^{4,8}$. Diversos trabalhos têm demonstrado a influência da pineal no eixo hipotálamo-hipófise-gonadal ${ }^{4,10,11}$, na adrenal ${ }^{3,12,14}$, diretamente sobre as gônadas ${ }^{1}$, nos rins ${ }^{5,13,20}$, como também apresenta interferência sobre os niveis plasmáticos de vasopressina ${ }^{7}$.

Além da melatonina, sabe-se que os esteróides sexuais também afetam o equilíbrio hidrossalino dos animais, em parte em razão da sua semelhança estrutural com os mineralocorticóides $^{9}$ e também por exercerem influência no controle da ingestão de água e de eletrólitos. Ademais, observou-se que existe variação da ingestão e excreção de água e eletrólitos de maneira cíclica em ratas, acompanhando o ciclo estral ${ }^{6}$. No entanto, a importância da ação dos esteróides sexuais sobre o controle do balanço hidroeletrolítico 
ainda necessita de mais estudos.

Alguns trabalhos referem que a glândula pineal regularia a secreção de mineralo e glicocorticóides ${ }^{22}$. Além disso, a adrenal de mamiferos apresenta receptores com alta afinidade pela melatonina, o que sugere uma ação direta da pineal sobre esta glândula ${ }^{3}$. A aldosterona, secretada pelo córtex da supra-renal, exerce importante controle do liquido extracelular, afetando principalmente a excreção de sódio e de água pelo sistema tubular renal. Sua ação não se limita aos rins, exercendo, também, influência no transporte de sódio e água em nivel das glândulas salivares e sudoriparas e do tubo digestivo. Assim, a aldosterona constitui importante elemento no controle do equilibrio hidroeletrolitico dos mamiferos ${ }^{9}$.

O rim apresenta receptores de melatonina na membrana basolateral do epitélio tubular proximal que atua na regulação da célula epitelial ${ }^{5}$. Alguns estudos demonstram modulação do AMP cíclico por meio do mecanismo de fosforilação ${ }^{20}$. Deve ser mencionado que a melatonina induz ao aumento da filtração glomerular de sódio e água no filtrado urinário e estimula o transporte tubular de sódio ${ }^{13}$.

A vasopressina é um hormônio liberado na neuro-hipófise que apresenta importante papel na regulação do balanço hidrossalino dos mamiferos. Estudos demonstram haver diferenças tanto na liberação de vasopressina quanto da sensação de sede durante o ciclo menstrual, ocorrendo diminuição desse hormônio durante a fase lútea em mulheres normais ${ }^{21}$.

Portanto, os dados da literatura mostram que a pineal estaria envolvida com a secreção de esteróides pelo ovário e adrenal, além de ter ação direta no sistema renal. O presente trabalho tem como objetivo analisar a influência da pinealectomia e da ooforectomia sobre o consumo de água e de solução salina em ratas adultas.

\section{Material e Métodos}

Foram utilizadas ratas (Rattus norvegicus albinus) adultas, virgens, pesando de 150 a $200 \mathrm{~g}$, que foram inicialmente acondicionadas em gaiolas individualizadas e com livre acesso à ração contendo dois tubos graduados: um com solução

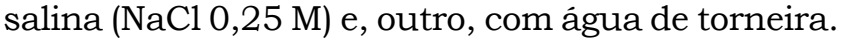
Após um periodo de adaptação de aproximadamente duas semanas, iniciou-se a anotação diária da ingestão de água e de solução salina, assim como a coleta de esfregaços vaginais para acompanhamento do ciclo estral. A seguir, os animais que apresentavam ciclos estrais regulares foram subdivididos, ao acaso, em quatro grupos: GI - sem manipulação (grupo controle - 20 ratas); GII - submetidos à ooforectomia bilateral (oito ratas); GIII submetidos à pinealectomia (12 ratas); GIV submetidos à ooforectomia bilateral e à pinealectomia (oito ratas). Todos os animais foram mantidos nas mesmas condições de temperatura, luminosidade e alimentação.

A ooforectomia foi realizada sob anestesia com éter etílico (Rhodia) por via inalatória, realizando-se inicialmente anti-sepsia com álcool iodado, colocação em decúbito lateral e tricotomia numa área de 2 por $2 \mathrm{~cm}$, próximo à angulação entre o rebordo costal e a musculatura dorsal. A seguir, incisaram-se a pele e o tecido celular subcutâneo e afastaram-se as camadas musculares até se atingir a cavidade peritoneal. Os ovários foram então localizados e pinçados, fazendo-se ligadura com fio de algodão (1-0) entre as tubas uterinas e os ovários. Após a retirada dos mesmos procedeu-se à sutura da incisão em plano único.

Para a pinealectomia os animais foram anestesiados, 15 dias após a ooforectomia, com pentabarbital sódico (Hypnol® - Cristália), na dosagem de $40 \mathrm{mg} / \mathrm{kg}$ por via intraperitoneal. Após anti-sepsia da parte superior da cabeça do animal e fixação do mesmo ao aparelho estereotáxico, procedeu-se à abertura da pele e do tecido celular subcutâneo até atingir o crânio, expondo-se a região do lambda. A seguir, a craniotomia foi feita com broca circular, expondo-se o encéfalo e retirandose a pineal com pinça apropriada. $O$ fragmento da calota craniana foi recolocado no local e realizada sutura em plano único da pele.

A profilaxia contra infecções no pósoperatório foi feita com a administração de Pentabiótico ${ }^{\circledR}$ (Wyeth), na dosagem de 0,4 ml por animal, por via intramuscular.

Após os procedimentos cirúrgicos, os animais foram novamente colocados nas gaiolas individuais, sendo que após 12 dias da última cirurgia, colheram-se novos esfregaços vaginais, para acompanhamento do ciclo estral. Anotou-se também a ingestão diária de água e de solução salina durante três meses consecutivos.

\section{Análise estatistica}

Para a análise dos dados, realizou-se análise de variância pelo teste de Bartlett e, a seguir, o teste $t$ de Student, sendo 0,05 ou 5\% o nivel de rejeição para a hipótese de nulidade.

\section{Resultados}

As ratas dos grupos ooforectomizados (GII e GIV), após 12 dias do ato cirúrgico, mostraram 
sinais colpocitológicos de falência ovariana, ou seja, os esfregaços vaginais eram atróficos, ao passo que as ratas do grupo pinealectomizado (GIII) apresentaram prevalência da fase de estro, ocorrendo estado de estro permanente na grande maioria dos animais, que se iniciou três semanas após a pinealectomia. Já os animais do grupo I tiveram ciclos estrais normais, com duração média de 4-5 dias.

Com relação à ingestão total de água ou de solução de $\mathrm{NaCl} 0,25 \mathrm{M}$, em função das fases do ciclo estral, os resultados não mostraram diferenças estatisticamente significantes tanto no grupo controle (GI) quanto no grupo pinealec-

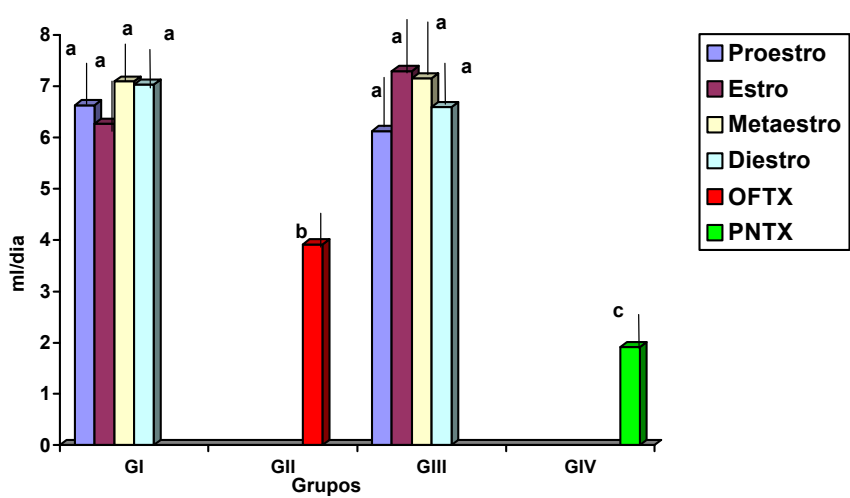

Figura 1 - Consumo de água nos quatro grupos estudados $(a \neq b ; p \leq 0,02)$. OFTX = Ooforectomia e Pinealectomia. PNTX = Pinealectomia.

tomizado (GIII) (Figuras 1 e 2).

A Figura 1 mostra a ingestão de água nos quatro grupos estudados. Notamos que ocorreu maior consumo de água no grupo ooforectomizado em relação aos outros grupos. Não houve diferença estatisticamente significante entre os grupos GI,

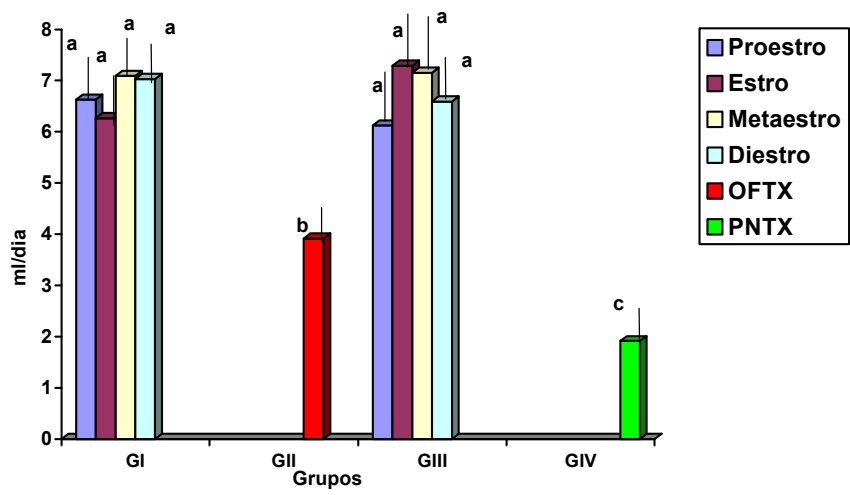

Figura 2 - Consumo de solução salina nos quatro grupos estudados ( $a \neq b \neq c ; p \leq 0,04$ ). OFTX = Ooforectomia e Pinealectomia. PNTX = Pinealectomia

\section{GIII e GIV}

Assinala-se na Figura 2 a ingestão de solução salina $0,25 \mathrm{M}$, em relação às fases do ciclo estral nos diferentes grupos. As ratas do grupo ooforectomizado (GII) mostraram redução estatisticamente significante da ingestão de solução salina em relação a qualquer uma das fases no grupo controle e no grupo somente pinealectomizado. Entretanto, observa-se que houve diferença estatisticamente significante entre as ratas do grupo GIV e as dos grupos GI, II e GIII.

\section{Discussão}

Quando analisamos as alterações induzidas pela ooforectomia em ambos os grupos de estudo (GII e GIV), notamos que os animais apresentavam esfregaços vaginais atróficos, com poucos elementos celulares e filamentos de muco, lembrando a fase de diestro do ciclo estral. Esta alteração decorreu da provável falta de atuação dos hormônios ovarianos, principalmente dos estrogênios, sobre o epitélio vaginal. Alguns autores acreditam que a fase de diestro seria conseqüente à falta dos hormônios ovarianos, tanto dos estrogênios quanto dos progestagênios ${ }^{20}$.

Em nosso experimento não notamos diferenças significantes com relação à ingestão de água e da solução de $\mathrm{NaCl}$ nas várias fases do ciclo estral da rata, tanto no grupo controle quanto no pinealectomizado. Assim, pudemos fazer uma média da ingestão hídrica para compararmos com os demais grupos.

Após a análise dos quatro grupos entre si, notamos que os animais que sofreram apenas ooforectomia apresentaram maior ingestão de água do que os outros grupos ( $\mathrm{p} \leq 0,02)$. Entretanto, esse mesmo grupo apresentou baixo consumo de solução salina $(\mathrm{p} \leq 0,04)$ quando comparado aos demais. Entre os mecanismos envolvidos para explicarmos esses dados, destacamos a diminuição dos esteróides de origem ovariana, ocorrida após a ooforectomia bilateral, o que levaria à redução da retenção hídrica pela perda de $\mathrm{Na}+$, ativando assim mecanismos de ingestão hídrica. Além disso, sabese que os estrogênios aumentam a sintese e a quantidade da matriz extracelular, principalmente no que diz respeito às glicosaminoglicanas, principais moléculas responsáveis pela retenção de água ${ }^{2}$. Porém, a progesterona poderia ter um efeito oposto, visto que possui atividade mineralocorticóide no rim $^{5}$.

Quando se procedeu somente à pinealectomia, não se observaram alterações na ingestão de água e de solução salina, em comparação ao grupo controle, o que indicaria falta de influência direta da pineal no equilíbrio hidrossalino dos animais, apesar de a melatonina atuar na filtração 
glomerular e no transporte tubular do sódio ${ }^{13}$.

No entanto, ao realizarmos a pinealectomia em ratas previamente ooforectomizadas, notamos redução acentuada da ingestão de solução salina em relação aos grupos controle, e pinealectomizado e ooforectomizado. Esses resultados indicam que a pineal deve apresentar ação sinérgica aos esteróides ovarianos em relação à ingestão de solução salina. Esta ação pode ser feita diretamente sobre os rins em razão da presença de receptores ou indiretamente através da influência sobre os ovários $^{13}$. Esse experimento apresenta ainda algumas incógnitas, que futuros experimentos poderão desvendar entre elas a atuação exata da melatonina sobre a excreção de sódio no rim.

Cumpre ainda ressaltar que os animais submetidos somente à pinealectomia apresentaram maior incidência da fase de estro, inclusive com indução ao estado de estro permanente, mostrando ação da pineal sobre o eixo hipotálamo-hipófiseovário. Deve ser mencionado que Prata-Lima ${ }^{15}$ descreveu um estado de estro permanente transitório em ratas pinealectomizadas, que voltaram a ciclar após a reposição de melatonina.

Com relação aos nossos achados podemos inferir que a ooforectomia e a pinealectomia exercem influência na ingestão hídrica e sódica da rata albina. No entanto outros trabalhos devem ser realizados para melhor investigar a ação da melatonina e dos hormônios sexuais no rim. Cumpre ressaltar que a patogênese da hipertensão essencial ainda é obscura e uma melhor investigação da relação entre a pineal, o ovário e o rim pode trazer mais conhecimentos para a solução do problema.

\section{SUMMARY}

Purpose: to evaluate the effects of oophorectomy and pinealectomy on the ingestion of water and $\mathrm{NaCl}$ solution by adults female rats.

Methods: forty-eight adult virgin female rats (Wistar EPM 1) weighing $200 \mathrm{~g}$ were kept on routine laboratory care and fed water and Purina rat chow ad libitum. The animals were random by divided into four groups: GI - maintained without manipulation as a control group $(n=20)$; GII - submitted to bilateral oophorectomy $(n=8)$; GIII - submitted to pinealectomy $(n=12)$; GIV - submitted to bilateral oophorectomy and pinealectomy $(n=8)$. All animals were maintained in individual cages. After three weeks the cycle phase was daily determined by vaginal smears and the volume of water and $\mathrm{NaCl}(0.25 \mathrm{M})$ solution was daily recorded for approximately three weeks.

Results: the main results were: 1) rats submitted to pinealectomy alone presented a greater frequency of the estrous phase, some of these undergoing persistent estrus; 2) the liquid ingestion (water and saline solution) did not alter during the phases of the estrous cycle; 3) rats submitted to oophorectomy presented greater water ingestion and after pinealectomy water consumption returned to normal levels; 4) the oophorectomized and pinealectomized animals and those only oophorectomized showed reduction in the average consumption of saline solution.

Conclusions: the data suggest that the ovaries and the pineal gland could have effects on the ingestion of salt and water in adult rats.

KEY WORDS: Pinealectomy. Salt and water intake. Oophorectomy.

\section{Referências}

1. Ayre EA, Pang SF. 2-[125I] iodomelatonin binding sites in the testis and ovary: putative melatonin receptors in the gonads. Biol Signals 1994; 3:7184.

2. Baracat EC, Simões MDJ, Haidar MA, Evêncio-Neto J, Novo NF, Rodrigues de Lima G. Histomorphometry of the postmenopausal endometrium after oral and transdermal estrogen replacement therapy. Menopause 1996; 3: 44-50.

3. Brown GM, Pang CS, Pang SF. Binding sites for 2[125I] iodomelatonin in the adrenal gland. Biol Signals 1994; 3:91-8.

4. Brzezinski A, Lynch HJ, Seibel MM, Deng MH, Nader TM, Wurtman RJ. The circadian rhythm of plasma melatonin during the normal menstrual cycle and in amenorrheic women. $\mathrm{J}$ Clin Endocrinol Metab 1988; 66:891-895.

5. Chan CWY, Song Y, Ailenberg M, Wheeler M, Pang SF, Brown GM, Silverman M. Studies of melatonin effects on epithelia using the human embryonic kidney-293 (HEK-293) cell line. Endocrinology 1977;138:4732-9.

6. Forsling ML, Peysner K. Pituitary and plasma vasopressin concentrations and fluid balance throughout the oestrous of the rat. J Endocrinol 1988;117: 397-402.

7. Forsling ML, Stoughton RP, Zhou Y, Kelestimur $\mathrm{H}$, Demaine C. The role of the pineal in the control of the daily patterns of neurohypophysial hormone secretion. J Pineal Res 1993; 14: 45-51.

8. Fritz MA, Speroff L. The endocrinology of the menstrual cycle: the interaction of folliculogenesis and neuroendocrine mechanisms. Fertil Steril 1982; 38:509-29. 
9. Guyton AC. Hormônios do córtex da supra-renal e funções reprodutivas da mulher fora da gestação e os hormônios femininos. In: Guyton AC, editor. Tratado de Fisiologia Médica. Rio de Janeiro: Guanabara S.A., 6 edição: 1986; p. 817-26.

10. Johsnson LY, Vaughan MK, Richardson BA, Petterborg LJ, Reiter RJ. Variation in pineal melation content during the estrous cycle of the rat. Proc Soc Exp Biol Med 1982; 169: 419.

11. Öcal-Irez T, Durmus G, Sekerkiran Y, Peker C, Uygur G. Effect of a pineal indolamine, 5-methoxyindole3-acetic acid, on the estrous cycle and reprodutive organs of female Wistar albino rats. Brain Res 1989; 493:1-7.

12. Persengiev SP. 2-[125I] iodomelatonin binding sites in rat adrenals: pharmacological characteristics and subcellular distribution. Life Sci 1992; 51:647-51.

13. Pishak VP, Kokoshchuk HI. The renal effects of melatonin in intact and epiphysectomized rats. Fiziol Zh 1995; 41: 23-6.

14. Poon AM, Liu ZM, Tang F, Pang SF. Cortisol decreases 2 [125I] iodomelatonin binding sites in the duck thymus. Eur J Endocrinol 1994; 130: 320-4.

15. Prata-Lima MF, Soares Jr JM, Reis RM, Reis JC, Salum R, Baracat EC. Desenvolvimento de policistose ovariana em ratas pinealectomizadas. Reprod Climat 1995; 10: 73-5.
16. Reichlin S. A pineal. In: Wyngaarden JB, Smith Jr LH, editores. Cecil Tratado de Medicina Interna.. Rio de Janeiro: Guanabara S.A., $16^{\circ}$ edição, 1986; cap. 1:1217-9.

17. Reiter RJ. The pineal gland. In: DeGroot LJ, Besser GM, Cahill Jr GF, Marshall JC, Nelson DH, Odell WD, Potts Jr JT, Rubenstein AH, Emil S, editores. Endocrinology. Philadelphia: W.B. Saunders Company, 1989; cap. 1:240-53.

18. Reiter JR. The pineal gland: An important link to the environment news. Physiol Sci 1986, 1:2025 .

19. Simões MJ. Aspectos morfológicos e morfométricos do endométrio de ratas nas subfases inicial, intermediária e final do metaestro e do proestro. Tese (Doutorado). São Paulo: Universidade de São Paulo, 1984.

20. Song Y, Pang CS, Ayre EA, Brown GM, Pang SF. Melatonin receptors in the chicken kidney are upregulated by pinealectomy and linked to adenylate cyclase. Eur J Endocrinol 1996; 135:128-33.

21. Wilkinson C W. Endocrine rhythms and the pineal gland. In: Physiology. Ruch T, Patton HD, editores. $21^{\text {th }}$ ed. Philadelphia: W.B. Saunders Company, 1991; cap. 2: 1239-61.

22. Zats M, Wang HM. Low salt mimics effects of dark pulses on circadian pacemaker in cultured chick pineal cells. Am J Physiol 1991; 261:1424-30. 